\title{
Article
}

\section{WebGIS Implementation for Dynamic Mapping and Visualization of Coastal Geospatial Data: A Case Study of BESS Project}

\author{
Giovanni Randazzo 1,2,3 , Franco Italiano $\left.{ }^{1,4}{ }^{(}\right)$, Anton Micallef ${ }^{1,5}$, Agostino Tomasello 1,6, \\ Federica Paola Cassetti ${ }^{1,6}$, Anthony Zammit ${ }^{1,7}$, Sebastiano D'Amico ${ }^{5}\left(\mathbb{D}\right.$, Oliver Saliba ${ }^{1,7}$, \\ Maria Cascio ${ }^{1}$, Franco Cavallaro ${ }^{1}$, Antonio Crupi ${ }^{1}$, Marco Fontana ${ }^{1}$, Francesco Gregorio ${ }^{1}$, \\ Stefania Lanza ${ }^{1,3}$, Emanuele Colica ${ }^{1,5}$ and Anselme Muzirafuti $1,8, *$ (i)
}

check for

updates

Citation: Randazzo, G.; Italiano, F. Micallef, A.; Tomasello, A.; Cassetti,

F.P.; Zammit, A.; D’Amico, S.; Saliba,

O.; Cascio, M.; Cavallaro, F.; et al

WebGIS Implementation for Dynamic Mapping and Visualization of Coastal Geospatial Data: A Case Study of BESS Project. Appl. Sci. 2021, 11, 8233 https://doi.org/10.3390/app11178233

Academic Editor: Hyung-Sup Jung

Received: 5 August 2021

Accepted: 2 September 2021

Published: 5 September 2021

Publisher's Note: MDPI stays neutral with regard to jurisdictional claims in published maps and institutional affiliations.

Copyright: (c) 2021 by the authors. Licensee MDPI, Basel, Switzerland. This article is an open access article distributed under the terms and conditions of the Creative Commons Attribution (CC BY) license (https:/ / creativecommons.org/licenses/by/ $4.0 /)$.
1 Interreg Italia-Malta-Progetto: Pocket Beach Management \& Remote Surveillance System, University of Messina, Via F. Stagno d'Alcontres, 31-98166 Messina, Italy; giovanni.randazzo@unime.it (G.R.); francesco.italiano@ingv.it (F.I.); anton.micallef@um.edu.mt (A.M.); agostino.tomasello@unipa.it (A.T.); federicapaola.cassetti@unipa.it (F.P.C.); anthony.b.zammit@gov.mt (A.Z.); oliversaliba90@gmail.com (O.S.); maria.cascio86@gmail.com (M.C.); frcavall@tin.it (F.C.); antoniocrupi5@hotmail.it (A.C.); marco.fontana92@yahoo.it (M.F.); gregoriofrancesco92@gmail.com (F.G.); stefania.lanza@unime.it (S.L.); emanuele.colica@umi.edu.mt (E.C.)

2 Dipartimento di Scienze Matematiche e Informatiche, Scienze Fisiche e Scienze della Terra, Università degli Studi di Messina, Via F. Stagno d'Alcontres, 31-98166 Messina, Italy

3 GeoloGISs.r.l. Spin Off, Via F. Stagno d'Alcontres, 31-98166 Messina, Italy

4 Istituto Nazionale di Geofisica e Vulcanologia, Osservatorio Etneo-Sezione di Catania, 95125 Catania, Italy

5 Euro-Mediterranean Centre on Insular Coastal Dynamics (ICoD), Institute of Earth Systems, University of Malta, MSD-2080 Msida, Malta; sebastiano.damico@um.edu.mt

6 Department of Earth and Marine Science (DiSTeM), University of Palermo, Viale delle Scienze Ed. 16, 90128 Palermo, Italy

7 Ministry for Gozo St. Francis Square, VCT-1335 Victoria, Malta

8 Laboratory of Geoengineering and Environment, Department of Geology, Faculty of Sciences, University of Moulay Ismail, BP. 11201 Zitoune, Meknes 50000, Morocco

* Correspondence: a.muzirafuti@edu.umi.ac.ma or muzansel@gmail.com

Abstract: Within an E.U.-funded project, BESS (Pocket Beach Management and Remote Surveillance System), the notion of a geographic information system is an indispensable tool for managing the dynamics of georeferenced data and information for any form of territorial planning. This notion was further explored with the creation of a WebGIS portal that will allow local and regional stakeholders/authorities obtain an easy remote access tool to monitor the status of pocket beaches (PB) in the Maltese Archipelago and Sicily. In this paper, we provide a methodological approach for the implementation of a WebGIS necessary for very detailed dynamic mapping and visualization of geospatial coastal data; the description of the dataset necessary for the monitoring of coastal areas, especially the PBs; and a demonstration of a case study for the PBs of Sicily and Malta by using the methodology and the dataset used during the BESS project. Detailed steps involved in the creation of the WebGIS are presented. These include data preparation, data storage, and data publication and transformation into geo-services. With the help of different Open Geospatial Consortium protocols, the WebGIS displays different layers of information for 134 PBs including orthophotos, sedimentological/geomorphological beach characteristics, shoreline evolution, geometric and morphological parameters, shallow water bathymetry, and photographs of pocket beaches. The WebGIS allows not only for identifying, evaluating, and directing potential solutions to present and arising issues, but also enables public access and involvement. It reflects a platform for future local and regional coastal zone monitoring and management, by promoting public/private involvement in addressing coastal issues and providing local public administrations with an improved technology to monitor coastal changes and help better plan suitable interventions.

Keywords: geographic information system (GIS); pocket beaches; coastal management; Interreg; climate change; remote sensing; drone; Sicily; Malta; Gozo; Comino 


\section{Introduction}

The numerous fields of application of geographic information systems (GISs) have now become an effective and irreplaceable element in the study of anthropogenic activities and natural phenomena, thanks to sophisticated technologies and the growing interest generated by the science of geographic information [1]. Geospatial data gathered on natural phenomena are required to construct maps and they are increasingly being used in GISs. These are systems that can capture, store, analyze, manage, and share data that are linked to geographical locations [2]. Over the years, GISs have become more dynamic, flexible, and accessible to users [3]. Once a GIS project has been prepared, web publishers can create and publish interactive web pages characterized by a high level of customization in the form of a WebGIS. It allows the information, including access to the maps published online, to be available to end users, such as citizens, tourists, and regional administrations, by using a common web browser by connecting from remote Internet locations [4]. The WebGIS combines two powerful technologies: GIS and the Internet, providing connectivity at the global level [5]; the result of this synergy results in greater ease in finding data, sharing analytical tools, and reaching a larger number of users [6,7]. Opdam [7] has argued that communication between science and society constitutes a relevant tool to optimize any planning and management. Veenendaal et al. [8] discussed the development of web mapping and presented a timeline of major web mapping events starting just after the creation of the World Wide Web with the publication of online maps in 1993 to the development of real-time services in 2017.

Examples of WebGISs have been developed in various fields, including radon risk management [9] and a risk assessment system for heavy metal pollution [10], georeferenced bibliographies [11], wastewater treatments [12] and water environment monitoring and management systems [13], planning and emergency phases in case of floods [14], transport infrastructure management [15], management of abandoned mines [16], civic education on peace and conflict [17], and as a landslide early warning system [18].

In the coastal field, examples of WebGISs have been utilized for visualizing coastal flooding vulnerability and planning for resiliency [19] and as a support to the management of coastal areas [20-22].

Application and interface servers have been used in WebGISs already consolidated by important public administrations, such as, for example, the Province of Belluno [23], Arpa Puglia [24], and the Metropolitan City of Venice [25].

The WebGIS approach can be defined as a set of geographic information services for the internet, based on a network that uses different forms of internet access to provide geographic information, analytical tools, and different GIS services [26]. The WebGIS is a GIS that uses web technology to communicate between the web application server and the end user client $[19,27,28]$. While incredibly powerful, the adoption of desktop GIS software has often lagged, due to several reasons, such as the expense of site licenses and higher-end computer hardware and the complexity of GIS software requiring high levels of training and expertise. With WebGISs, users do not need to purchase and install expensive GIS software to access and work with maps and databases [29]. Also, users do not need to become experts in sophisticated GIS applications, since the functionality is made available through a regular web browser and an integrated viewer with a simple, user-friendly interface. Otherwise, GIS tools and data are often beyond the reach of ordinary citizens with an interest in a particular place-based decision problems [19].

Implementation of WebGISs applied on pocket beaches (PBs) of Sicily, Malta, Gozo, and Comino represents one of the outputs of the Pocket Beach Management and Remote Surveillance System project (BESS), co-financed by the European Union (European Regional Development Fund, within the Operative Program Italy-Malta 2014-2020), coordinated by the Department of Mathematical and Computer Sciences, Physical Sciences, and Earth Sciences (MIFT) of the University of Messina (UNIME). The Maltese partners included the Ministry for Gozo and University of Malta (represented by the Euro-Mediterranean Center on Insular Coastal Dynamics (ICoD)); the Sicilian partners included the Department of 
Earth Sciences (DiSTeM) of the University of Palermo (UNIPA) and the National Institute of Geophysics and Volcanology (INGV).The aim of the BESS project was to achieve, following a large number of studies, a coastal monitoring platform that contained geological and morphological data, biological and sedimentological analysis, bathymetric information, and aerial photogrammetric and anemometric data. This platform was developed to allow the management of these input data within a WebGIS to study the evolution of 134 PBs in Sicily and Malta.

PBs represent coastal features characterized by their evolving shape, their geomorphological influence on sedimentary input, and their ecological value. These enclosed beaches are small beaches set between headlands that diffract or refract incoming waves [30-32]. The term "pocket beach" describes a beach controlled by a geological structure or a human structure, such as a groin or jetty [33-35] and they are common along rocky coasts throughout the world $[36,37]$.

Detailed studies of PBs have previously been conducted [35,37-42], PBs are widespread throughout the entire coastline [42-44] and the characteristics of their exceptional natural landscape make them very attractive to tourists. Natural and man-made PBs are frequent elements of the Sicilian and Maltese coast and are often the most attractive segments of rocky coasts, forming a hub for tourist activity.

The main contributions of this paper are to provide:

- A methodological approach for the implementation of a WebGIS necessary for a very detailed dynamic mapping and visualization of geospatial coastal data.

- The description of the dataset necessary for the monitoring of coastal areas, especially the PBs.

- A demonstration of a case study for the PBs of Sicily and Malta by using the methodology and the dataset used during the BESS project.

In this paper, the process followed during the implementation of the BESS WebGIS is presented. The WebGIS contains the dataset obtained from a series of monitoring procedures carried out with a holistic approach during the BESS project. The project was adopted in the aim of reaching a turning point in terms of management of the geological and naturalistic heritage represented by the PBs, by considering, above all, implications of the well-being of society that arise from the protection of highly valued tourist sites. This paper describes how WebGIS technology was employed for geospatial data representation and dynamic mapping of the PBs. It further demonstrates the process of the implementation of a WebGIS, which is considered to be useful in terms of mapping, monitoring, and sensitization of coastal geomorphological peculiarities, namely the PBs.

\section{Materials and Methods}

\subsection{Study Area}

The islands of Malta and Sicily are characterized by distinctive environmental and climatic similarities, as they are both located in the center of the Mediterranean Sea (Figure 1). They have, in fact, many geological similarities since they form a spur on the northern edge of the African continental plate that includes Malta, SE Sicily, the Pelagian Islands, eastern Tunisia, and the northwestern Libyan shelf [45].

During the last one million years, following eustatic variations, both islands have alternately been physically linked to each other and to the Italian peninsula [45-47]. In particular, during the Last Glacial Maximum they were physically connected by an isthmus and formed a territorial unicum, located in the center of the Mediterranean, acquiring the shape of the three-legged island [48]. 

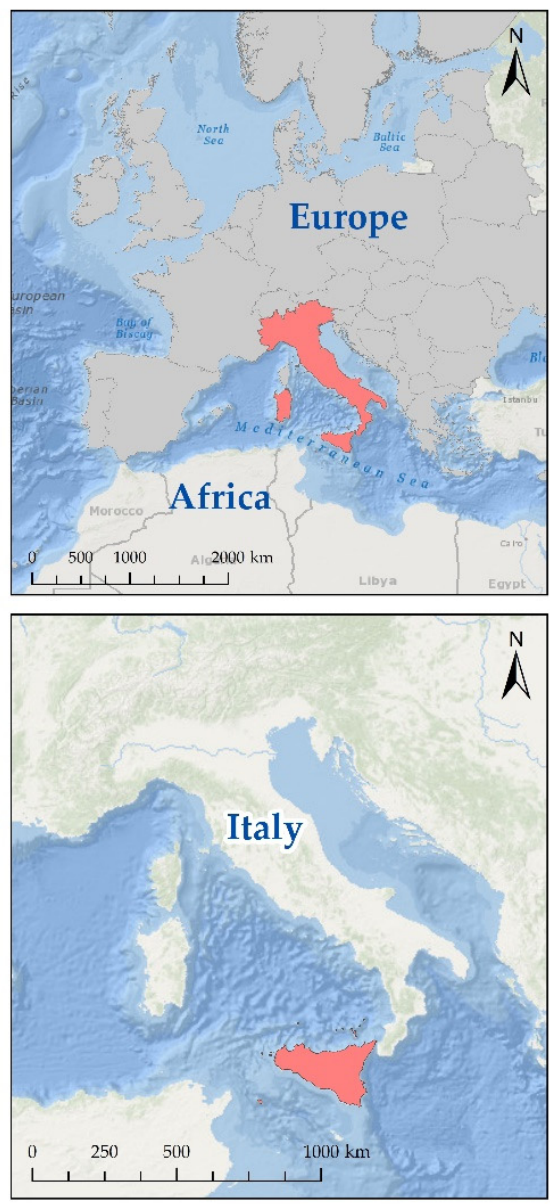

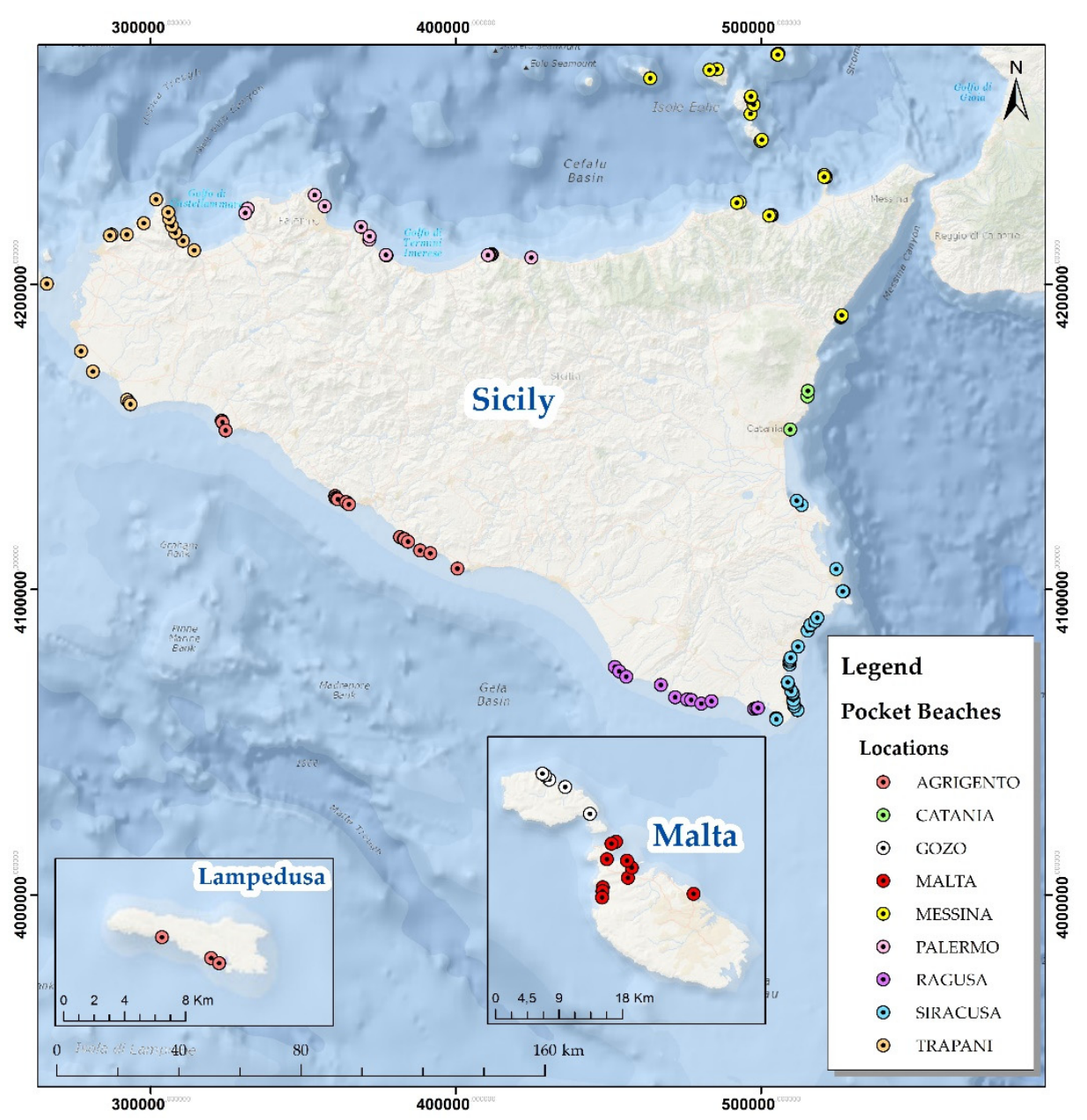

Figure 1. Geographical framework of the study area (map adapted from ESRI, GEBCO, NOAA, National Geographic, Garmin, HERE, Geonames.org, and other contributors).

Despite this, while Sicily shows a great geodiversity, due to the geologically complex history dating from the Paleozoic to Pleistocene periods, involving metamorphic, magmatic, and sedimentary outcrops, the geology of the Maltese Islands are predominantly composed of marine sedimentary rocks, mainly limestone with subsidiary marls and clays [49,50], deposited in shallow marine conditions between the late Oligocene and Miocene age [49], with sporadic occurrences of quaternary deposits in some areas (Figure 2).

Sicily is the second largest island in the Mediterranean Sea, with a $1623 \mathrm{~km}$ coastal length, divided into $26 \%$ of rocky coasts and $74 \%$ of sandy and/or pebbly beaches [51,52]; among them 110 PBs consist of both natural and artificial features, having different dimensions and various planform geometries, differently exposed to incident wave energy and with limited sediment sourcing by drainage basins.

The Maltese Archipelago consists of the three main islands of Malta, Gozo, and Comino and a number of other minor islands and rocks [53,54]. The entire coastline measures $272 \mathrm{~km}$ [55], with the predominant shore type being rocky $(90.5 \%)$; sand and shingle shores only comprise $2.4 \%$ of the remaining coastline [56]. The coastal morphology of the Maltese Islands has been largely determined by tectonic activity, primarily in the Holocene period, which has been uninterrupted to present day [57].

The PBs of the Maltese islands (22 PBs) are exclusively small (the largest, Ghadira, is only $1 \mathrm{~km}$ long), flanked between rocky headlands or anthropogenic infrastructures, and there is limited sediment exchange between beaches located at various spatial scales [58,59]. 

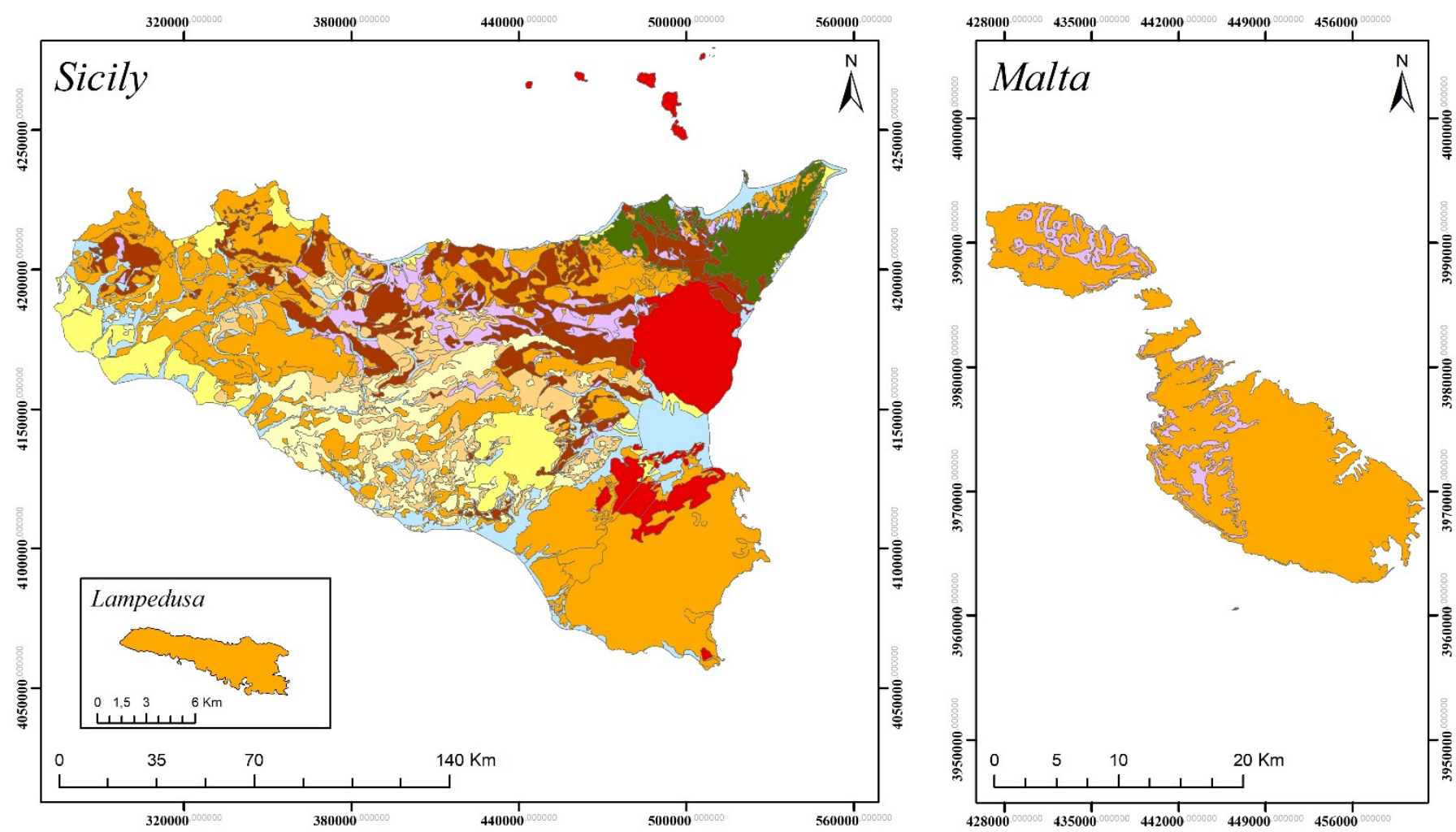

Recent deposits

Marine deposits

Limestone and Dolomites

Evaporites

\section{Clay \\ Terravecchia Formation \\ Flysch \\ Vulcanite \\ Metamorphic}

Figure 2. Lithological framework of Sicily and the Maltese Archipelago. (Revised from Geologic Map of Sicily-Lentini and Carbone, 2014).

\subsection{Dataset Preparation and Data Description}

The data loaded into the BESS GIS are diverse (Table A1) and concern all the parameters that allow a detailed geo-characterization of the PBs present in Sicily, Malta, Gozo, and Comino. A synthesis of these data fed the WebGIS, opening the project results to a wide stakeholder audience.

Two flight surveys were conducted using different DJI (Mavic 2, 210 RTK, 600 Pro) drones during the Spring-Summer season of 2019 and Autumn-Winter season of 2019/2020. These types of drones were chosen due to their size, flight time, flight safety, stability, and the payload of sensors they can carry.

DJI Mavic 2 is a small UAV equipped with an excellent Hasselblad camera, with a one-inch sensor. It has a collapsible frame and two powerful landing lights, plus collision sensors on all sides. This drone combines the high technology of stability, flight safety, and miniaturization of electronics. DJI 210 RTK is a large UAV equipped with a flight terminator and parachute. It has upper, lower, and front anti-collision sensors and a sophisticated system (DJI Airsense) for signaling proximity to traditional aircrafts. The drone is waterproof and is equipped with an RTK (real-time kinematic) system. DJI 600 Pro is a large UAV equipped with a flight terminator and parachute. It has 3 GPS and 3 inertial attitude and altitude systems (IMU). It is powered by 6 batteries, can carry a maximum of $5 \mathrm{~kg}$ payload, and has a flight range of about $30 \mathrm{~min}$ without any payload.

The acquired images were processed with Pix4D mapper software to build veryhigh-resolution orthophotos of $1.6 \mathrm{~cm}$ spatial resolution. In addition, satellite images and historical maps were also used. Based on these drone orthophotos, satellite images, historical maps, data related to geomorphological-sedimentological, geometric param- 
eters, lithology, bathymetry, land-use/land-cover mapping of Sicilian and Maltese PBs were extracted.

The drone orthophotos were geo-referenced through on-ground placement of markers whose locations were acquired using GPS RTK (GNSS TOPCON Hiper HR composed of base + rover) [60,61]. Following Bowman et al. [42], Storlazzi and Field [62], and Narcross et al. [63], the orthophotos were also used to define the geometry and morphological characteristics of PBs.

The next step, considering the various ground control points (GCPs), was to build the digital surface models (DSMs) of the PBs and then derive the slopes expressed as a percentage with linear interpolation (to express the details at a better resolution), finally classified into 4 categories (0-5-10-15\%). Beaches that were difficult to reach, such as nature reserves and private beaches or those too close to airports or military installations, were analyzed using both free (Sentinel-2 with $10 \mathrm{~m}$ pixel spatial resolution) and commercial (WorldView-2, $50 \mathrm{~cm}$ pixel spatial resolution) satellite images.

The satellite images were also used to derive the bathymetry [64-66], processed by the ENVI software and then reclassified by QGIS version 3.4 (Open Source Geospatial Foundation, Chicago, USA). The reclassification was necessary to differentiate each beach because of different degrees of resolution, depending on multiple factors, such as presence of Posidonia oceanica, clouds, sun, and quality of previous bathymetric data. Using this bathymetry, submerged beach closure depth was calculated, following Lisi et al. [67], and the mapping of the Posidonia oceanica was performed for the whole number of PBs following Tomasello et al. [68]; Ventura et al. [69] and Rende et al. [70].

Beach sediment samples were collected along 3 shore-perpendicular transects on beaches with a shoreline length $>300 \mathrm{~m}$ (and along 1 transect for $<300 \mathrm{~m}$ ). During the first field survey, sediments at backshore, shoreline, and $-1 \mathrm{~m}$ were collected; this was restricted to a shoreline sample in a second survey. The samples were then transported to the laboratory and subjected to particle size analysis.

Land use/land cover [71] and lithology were surveyed from different sources (maps, drones, and satellite); a buffer of $0.5 \mathrm{~km}$ for land use and $1 \mathrm{~km}$ for lithology was used.

An additional project output involved the establishment of a Wi-Fi-connected remote surveillance network of ten sites, with a central control room feeding a specific sector of the GIS. Each site was equipped with one or more cameras and with an anemometer powered by solar panels. In three of these sites, the Italian National Institute of Geophysics and Volcanology (INGV) placed a monitoring system composed of accelerometric/velocimetric devices aimed at detecting the microseismicity induced by sea waves in three selected PBs.

The data ordered within the GIS were uploaded within the WebGIS, dividing them into two macro areas: raster and vector file format. Raster images are those with variable resolution, depending on the object they show and the degree of detail they intend to represent, including orthophotos, satellite images, and bathymetry. Vectors are instead points, lines, and polygons, imported by GIS, which contain an attribute table with all the element details within the shapefile-sediment samples, in situ photo collections, remote surveillance systems (points), geometric and morphological parameters (points, lines, and polygons) and lithology, land use, Posidonia oceanica (polygons). The coordinate system chosen was WGS84 33N (EPSG: 32633). The data uploaded to WebGIS amounted to about $200 \mathrm{~GB}$.

\subsection{Methodology}

The WebGIS platform allows the display of geospatial data on the website with Open Geospatial Consortium (OGC) protocols such Web Map Service (WMS), Web Feature Service (WFS) and Web Feature Service with transactions (WFS-T), and Web Coverage Service (WCS) and allows displays on a web page both from PC and smartphone. The creation of the maps of the layer components, the organization, and the preparation of the data was carried out through the QGIS Desktop program version 3.4 and, subsequently, following various operations including the management of the scales, basic levels, meta- 
data, preparation for QGIS server, and additional function settings, these were displayed within the Lizmap web client application (Figure 3). The various geographic data, once obtained and stored in GIS, were published and transformed into geo-services into WebGIS. A geo-service allows the consultation, the processing, and the return of geographic data through the internet. OGC defines the common aspects of the OpenGIS Web Service (OWS) and provides a software interface through which other applications' clients can access and use geospatial data located remotely. This communication is based on extensible markup language (XML) through the HTTP communication protocol; so that the service that is made available is independent to the platform and operating system. The publication of geo-services can take place in two different ways:

- WebGIS: publication of geographic information data through an interactive web page that does not require the use of specific GIS software for their use.

- Geo web service: a particular architecture that allows the return of geographic data located remotely through specific protocols, following a request made either through a simple web browser or through specific client applications.

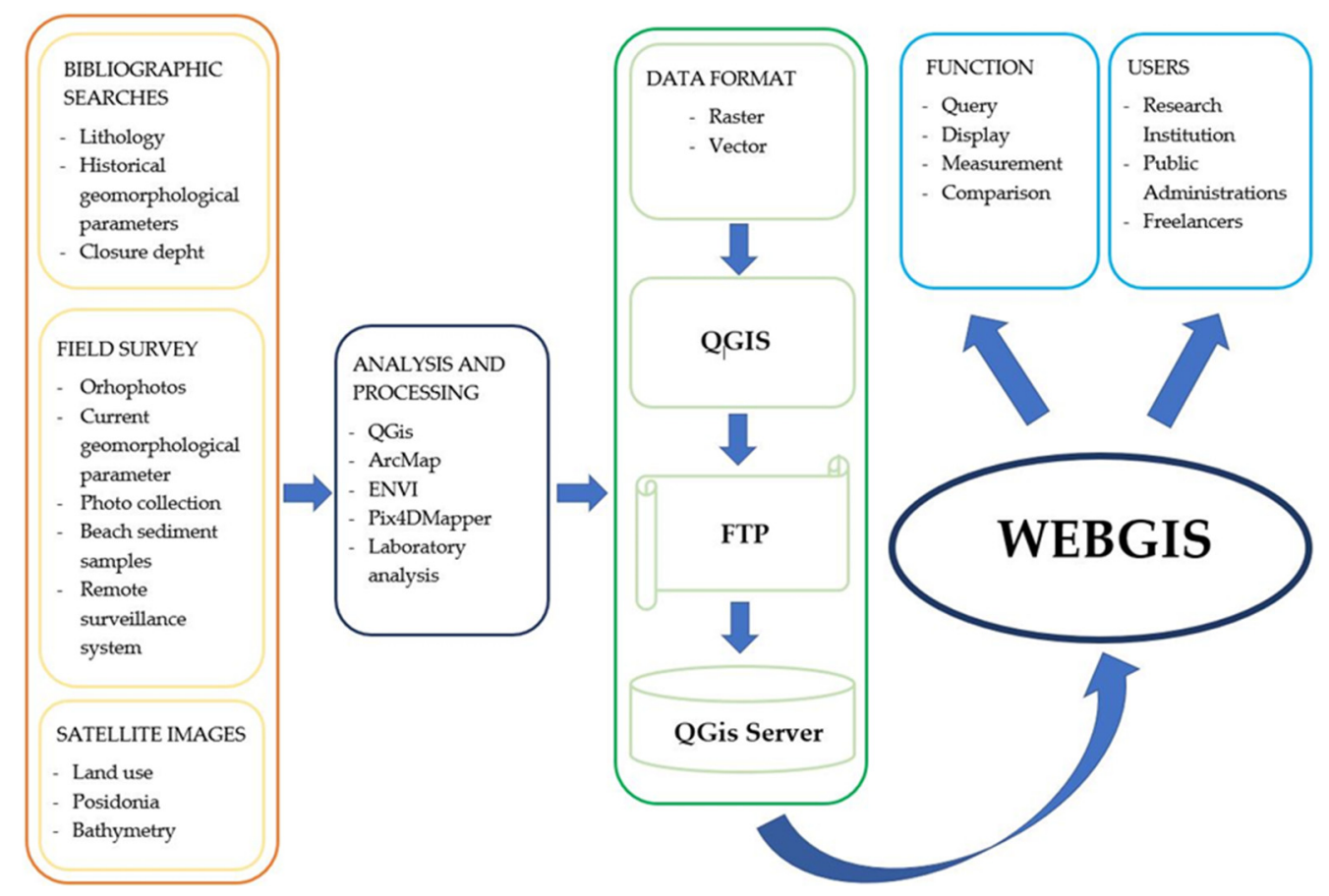

Figure 3. Chart flow methodology of BESS WebGIS implementation.

Both these approaches were used for the BESS project to allow data visualization both remotely (GIS desktop) and via WebGIS. The OWS services used for the usability of the data were WMS, for raster data, and WFS, for vector data. The database was made usable as a geo-service through the QGIS Server application and was subsequently made accessible online through the Lizmap client interface. This application was chosen because it uses the same libraries as the QGIS Desktop application and, therefore, it allows maps with complex graphical representations to be published with the same characteristics as the Desktop application, while keeping all the parameters defined in QGIS desktop unchanged. The main advantage of QGIS Server is undoubtedly the integration with QGIS Desktop itself; it also does not require specific skills in the field of publishing web services and significantly shortens processing times. Once QGIS Server has created the standard geoservices (WMS/WFS), the Lizmap client interface can publish data online. This interface was chosen as it can be configured from a plugin (Lizmap) within QGIS Desktop and does not require special knowledge of programming languages. While in the present study, a dataset with data of different spatial resolutions was used, the BESS WebGIS allows the visualization of information at the scale of 1:2257. This is in accordance with the Open 
Street Map basemap included. However, this scale can be improved and reach 1:1128 by disactivating the underlying basemap.

\section{Results}

\subsection{WebGIS Visualization and Mapping}

By accessing the WebGIS platform via the following link (http://51.38.247.246/ mylizmap/lizmap/www/index.php/view/map/?repository=bess\&project=bess (accessed on 8 February 2021)), a screen will appear where it will be possible to manage the functions of the service (Figure 4); the left part represents the toolbar and the various layers present, while the central and right part is dedicated to navigation. While the default language is in Italian, a user can choose the name of the various layers and then put it in any convenient language.

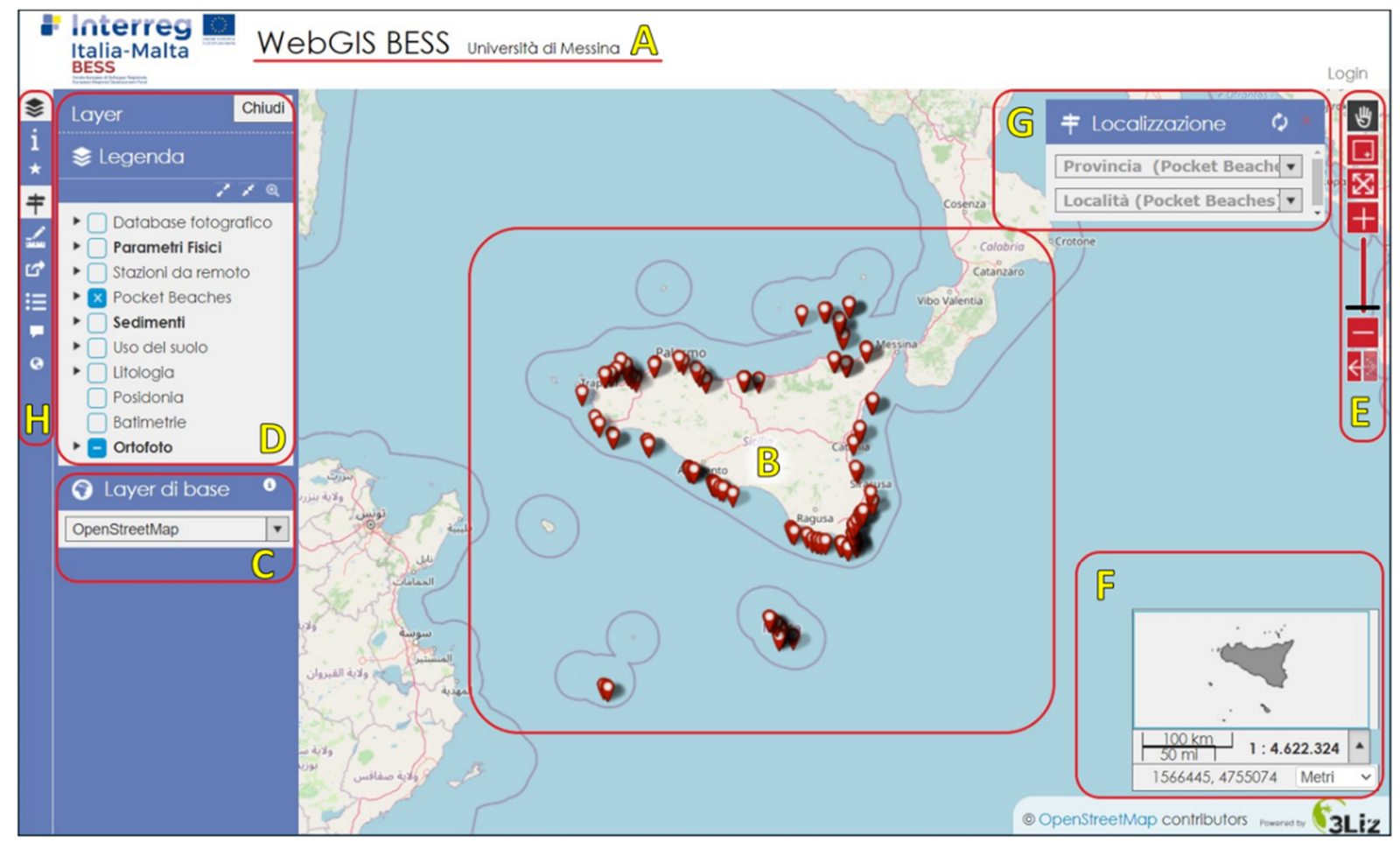

Figure 4. WebGIS home screen with yellow letters indicating the main default functions.

The defaults functions and features indicated in the WebGIS home screen (Figure 5) are illustrated below:

A. Title of the web window reflecting the container of all the information relating to the project.

B. Initial map with the default scale set

C. Tool that allows for activating or deactivating of a basemap layer from the map background. In this study, OpenStreetMap was used due to the amount of information it contains.

D. The legend lists the various data layers (raster and vector) in order of overlap, inserted within the map; both single and multi-layers may be accessed. Some layers can be grouped according to the composition of the project. By clicking on the small triangle on the left of each layer, the relative symbol will appear, opening the data related to the information layer. By selecting a specific layer, it will be possible to obtain relevant information, like its spatial extension, or to modify, with various levels, its degree of opacity. Once any layer is activated, it will appear in the map according to a presentation style previously created in QGIS. By clicking with 
the left mouse button on any vector element, a popup window will appear on the right containing the information of the objects positioned in that particular point (Figure 5).

E. This tool allows navigation of the map through various buttons:

(1). « Pan — the horizontal shift (the hand sign symbol) allows movement around the map by clicking and holding the left mouse button. It is also possible to use the mouse wheel, both forwards and backwards, thus activating the modification of the scale, keeping the mouse cursor in the center of the map;

(2). $\square$ Zoom window (red plus symbol), which allows a specific zoom by dragging the pointer in order to draw a rectangle, which then defines the area of interest to be scaled;

(3). Zoom to initial map extension's symbol allows zoom of the starting map;

(4). $\quad$ Zoom in-zoom out's symbol allows selection of the zoom level through a scale bar;

(5). Previous and next zoom: these two indicators allow one to scroll through the zoom history.

F. The panel displaying the map overview uses a blue square highlight to indicate the current surface shown on the map. Furthermore, a scale bar and coordinates of the cursor point position based on the reference system set are also shown inside this panel, in this case UTM WGS84 33N. It is possible to change the map view by moving the blue square on the overview. In the lower right corner, there is also the exact geographical position. Finally, a small drop-down menu also allows choosing the unit of measurement (meters/degrees/degrees and minutes/degrees, minutes, and seconds).

G. The location tool allows a specific position to be reached, based on any categorized item of the project, in this case, an individual PB under study. These actions are initially carried out by identifying the area in which the various PBs are grouped, for example, the Sicilian Provinces (Messina, Palermo, Catania, Syracuse, Ragusa, Agrigento, and Trapani), Malta, Gozo, and Comino. Once this parameter has been identified, the beaches discriminated for that area will appear in the second window; by selecting the latter, it will appear on the map to the same extent as the selected geometric object (Figure 6). The activated layer corresponds to the orthophoto.

H. Toolbar

1. $\cong$ Layer symbol activates or deactivates the layer management panel and its legend (D)

2. $\quad 1$ Information allows obtaining information relating to the map description, set properties, contacts of the person responsible for the published data, and other features.

$\star$

3. Star tool allows selecting and filtering the geometries of a single layer into the map using various tools, and, subsequently, displays in the attributes table.

4. Localization symbol activates or deactivates the localization tool (G). 
5.

By clicking Ruler tool it is possible to choose the type of the activated measure (length, area, and perimeter).

\section{๘}

6.

Permalink allows users to obtain an external link that will allow them to save the map in the exact extension, projection, and scale of that moment.

7. $\quad$ : Table attribute symbol activates the attribute tables of the vector layers present in the project, with the possibility to sort and select the fields, as well as to filter them in order to make comparisons.

8. $\quad$ Popup (message) symbol represents the pop-up window for the information of the selected data.

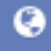

Atlas (globe) symbol represents the atlas, or a sequential display of a given layer. In this case the single PBs layer was chosen for display. It is also possible to automatically reproduce the sequence of the beaches using the "play" button.

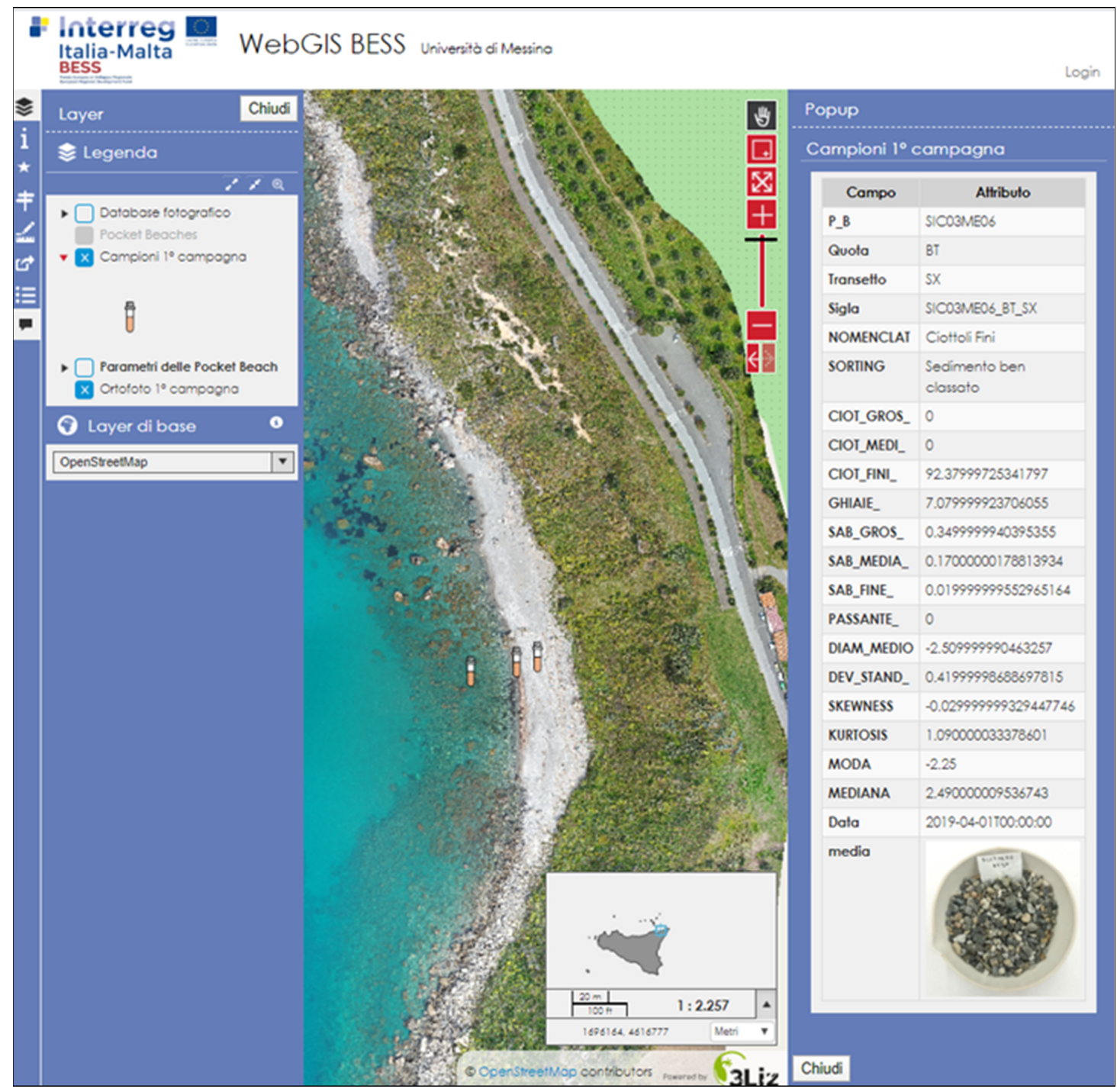

Figure 5. Display of the platform with the opening of a popup relative to the grain size information about the shoreline sample of Capo Milazzo's PB. 


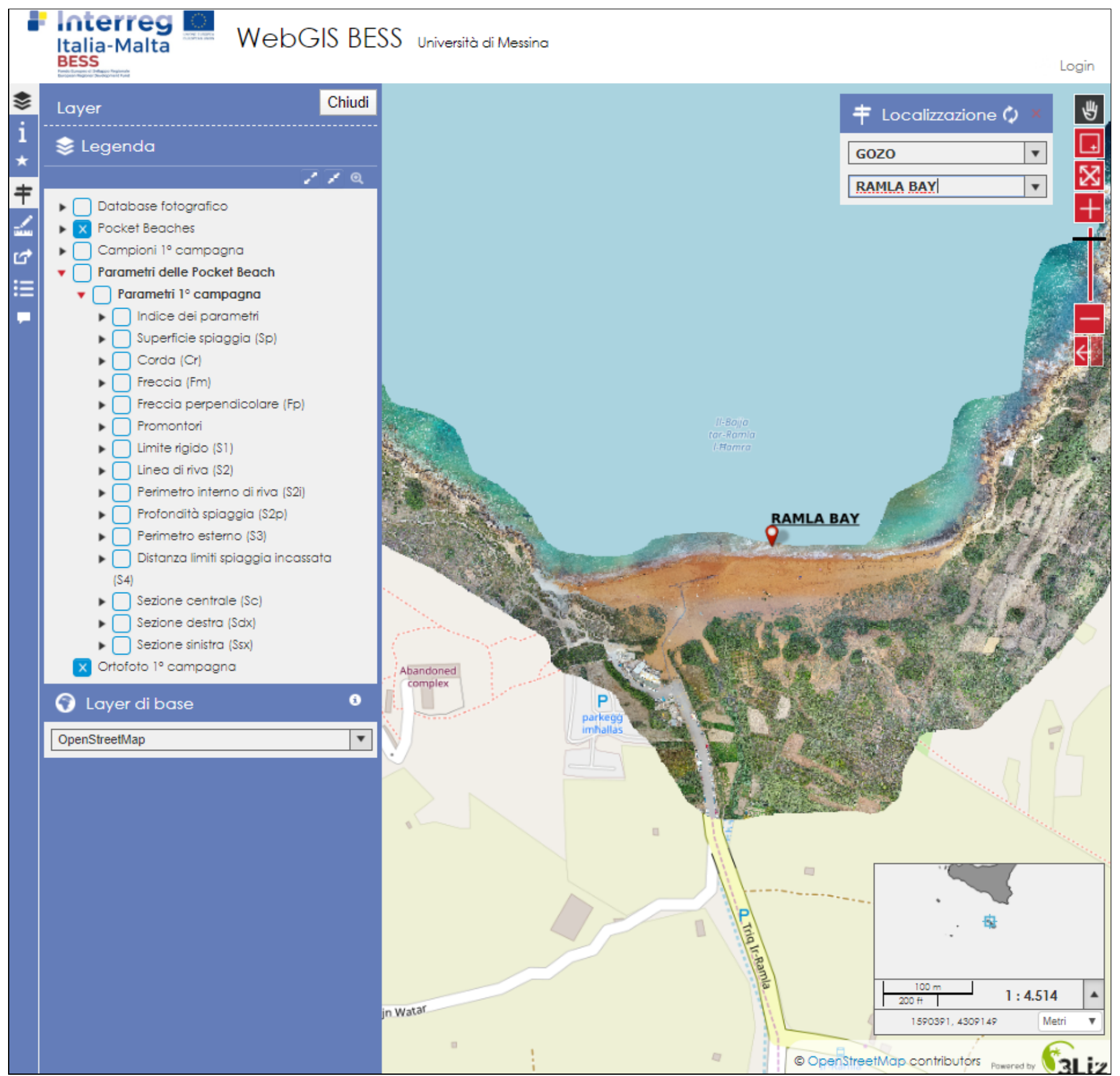

Figure 6. Visualization on the WebGIS platform of the PB of Ramla Bay (Gozo).

Starting from these instruments WebGIS can be used to investigate the different layers of the project, crossing queries and comparing information. This platform offers the possibility of turning on and off layers of different or the same areas, as well as of different time intervals; this, in both cases, shows, in detail, the characteristics of the PBs and their evolution over time.

\subsection{Examples of Comparison}

Regarding the orthophotos, there is a possibility to view and overlap them in order, to visually notice the differences, in particular by playing on the opacity of one of the two to compare them more clearly. To make the comparison between orthophotos more effective, it is also possible to activate the layers relating to the respective shorelines (Figure 7). For example, certain geomorphological differences have also been digitized and shown within 
the layers concerning the geomorphological parameters, which can be interrogated to view their characteristics.

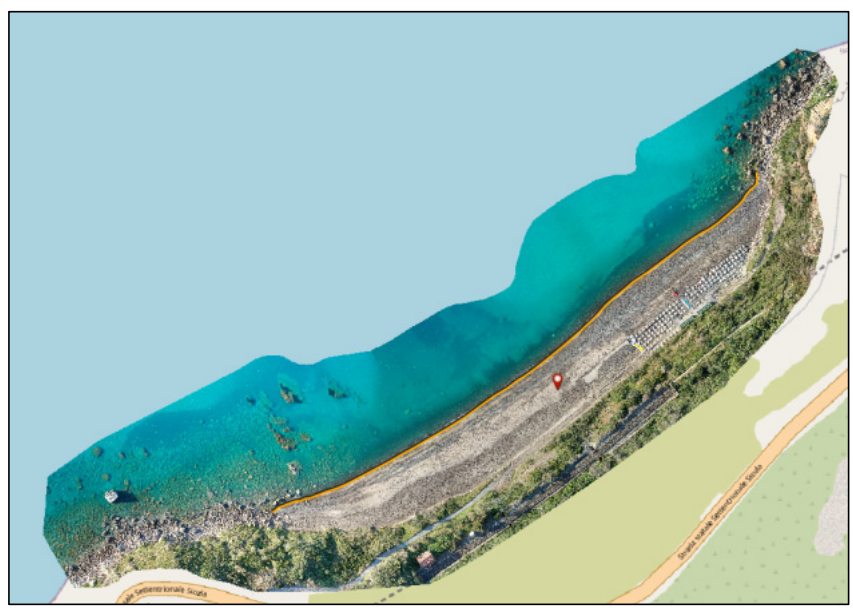

(a)

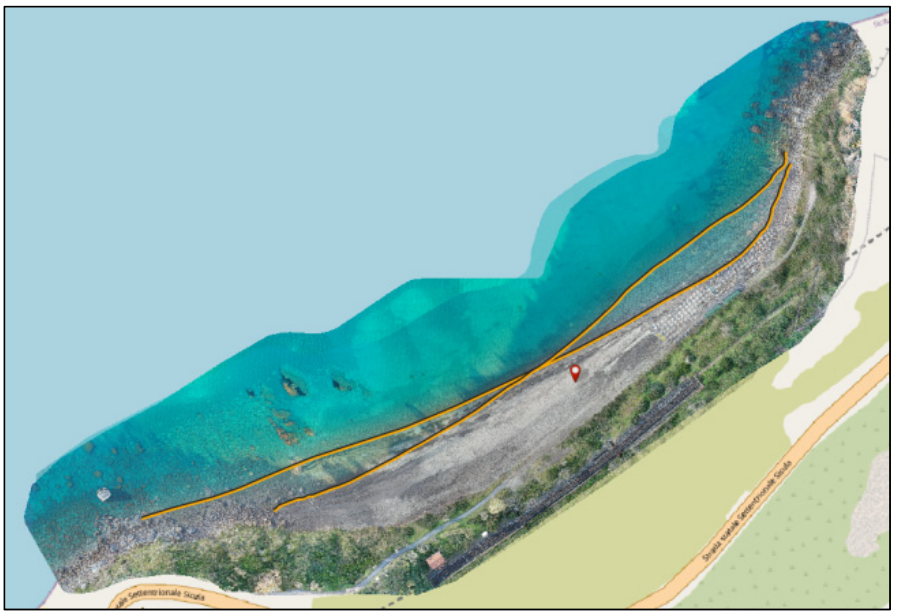

(b)

Figure 7. The figure shows a comparison of the pocket beach of Rais Gerbi (Palermo) in two different time intervals through the management of opacity: (a) Spring-Summer Season; (b) overlap of Autumn-Winter season on Spring-Summer season. The respective shorelines are highlighted in orange.

Among the various combination that can be made by switching different layers on or off, it may be useful to combine lithology, samples and photo collections. Thanks to this overlap, it is possible to query the map in order to notice an affinities or differences at the mesoscale. The following example (Figure 8) shows how, by clicking on the photographic icon, the popups relating to both the latter and the underlying lithology layer will open simultaneously. In Figure 9, on the other hand, by clicking on the nearby shoreline sample, the popup will show its characteristics.

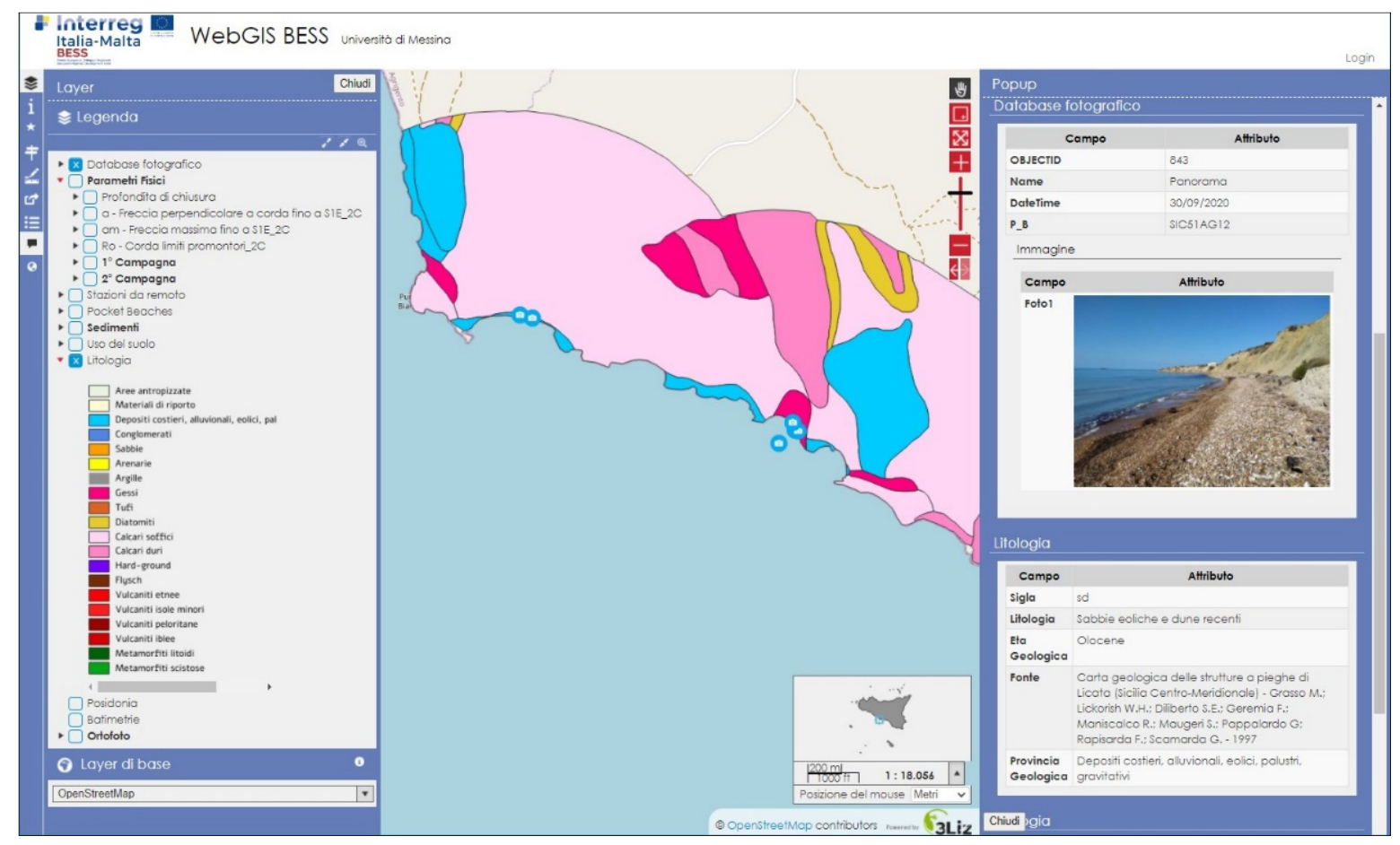

Figure 8. WebGIS platform that shows the overlap between samples, lithology, and photo collection of the pocket beach of Palma di Montechiaro (Agrigento). On the right, the popup between the last two obtained by clicking on the photo collection. 


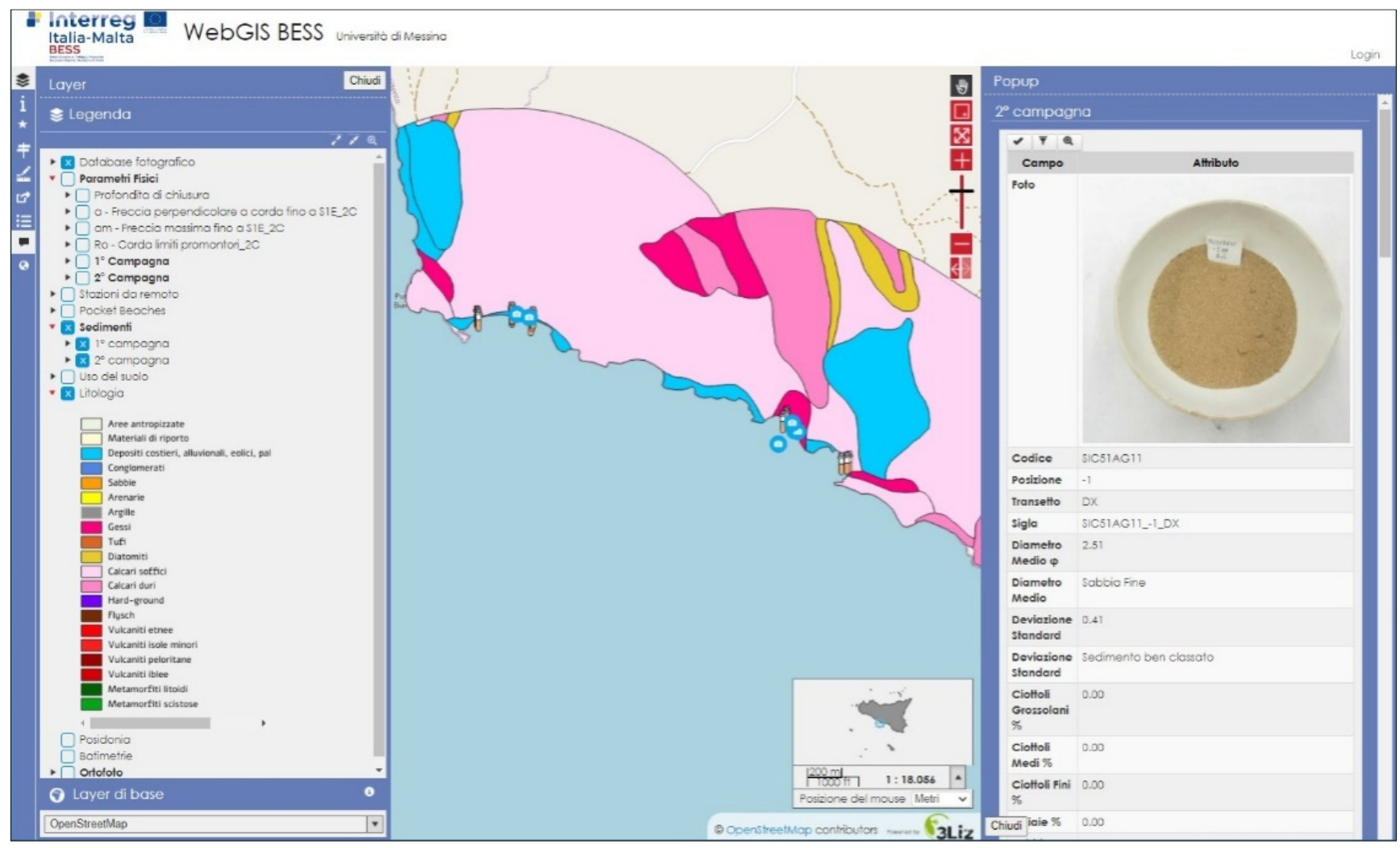

Figure 9. WebGIS platform that shows the overlap between samples, lithology, and photo collection of the pocket beach of Palma di Montechiaro (Agrigento). On the right, the pop-up of the shoreline sample obtained by clicking on the photo collection.

It is evident, through these simple steps, how it is possible to notice the similarities between the lithological characteristics of the outcrop, in this case metamorphic, and the respective photographs of the study area and the nearby beach sediments.

Another comparison can be made with regard to the sedimentological analysis, in order to learn the differences between the grain size and other statistical parameters (Figure 10). To compare samples related to the same vector layer, the selection tool should be used to click the geometries to study. By clicking the filter button, the attribute table of the selected geometries may be viewed.

It may be useful to compare the surfaces of the beaches of successive surveys. Figure 11 shows how, by activating the respective layers and clicking on them in the map, the user can view both the visual and area differences by observing the popup.

One of the layers present in the WebGIS consists of the mapping of Posidonia oceanica proximal to the PBs; through this platform, it is possible to observe its distribution according to the various bathymetric zones. In Figure 12, for example, it emerged that Posidonia oceanica develops mainly between 5 and $20 \mathrm{~m}$ deep. 


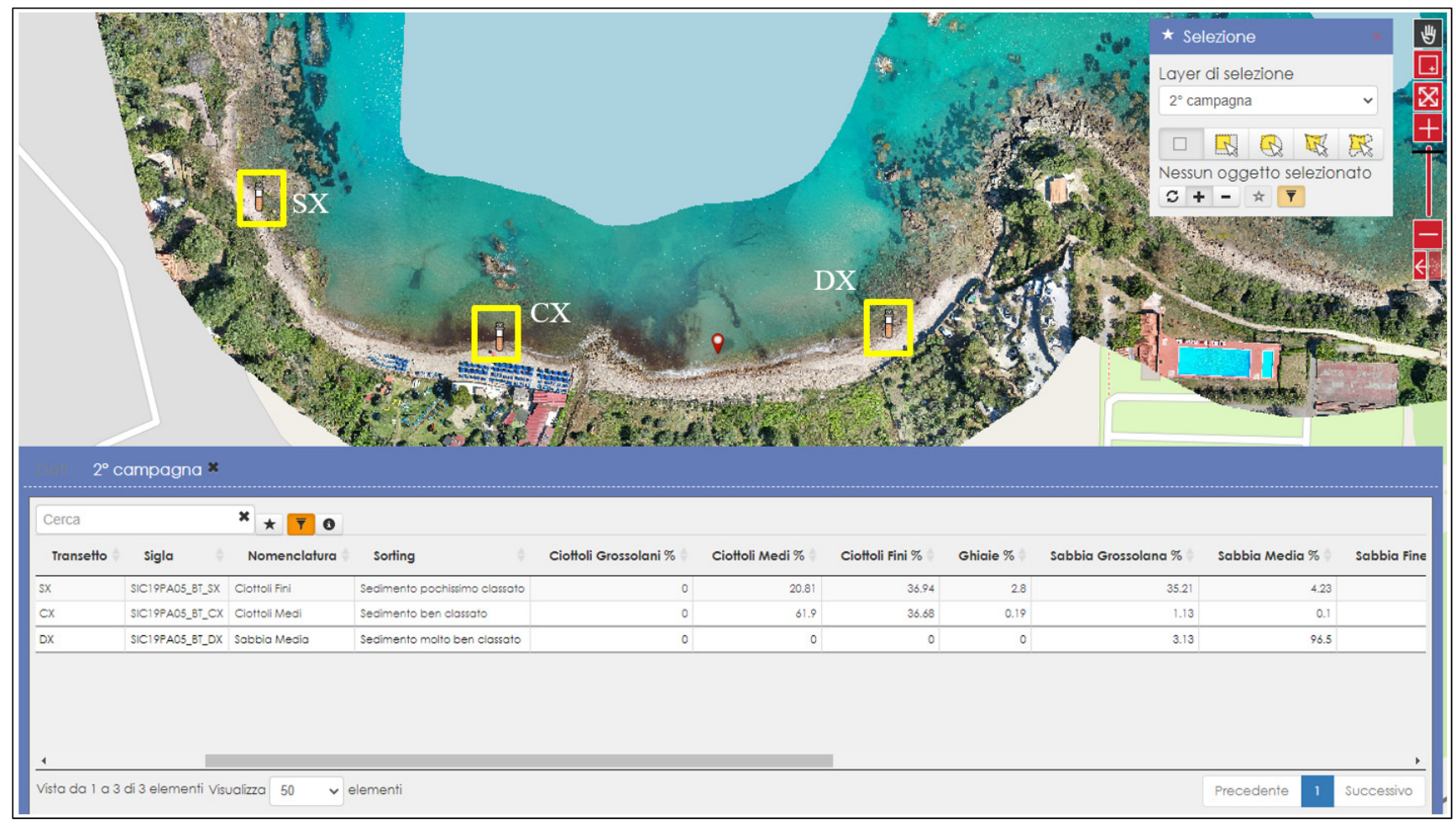

Figure 10. Example of comparison between beach sediments for three different transepts taken along the PB of Cefalù (Palermo).

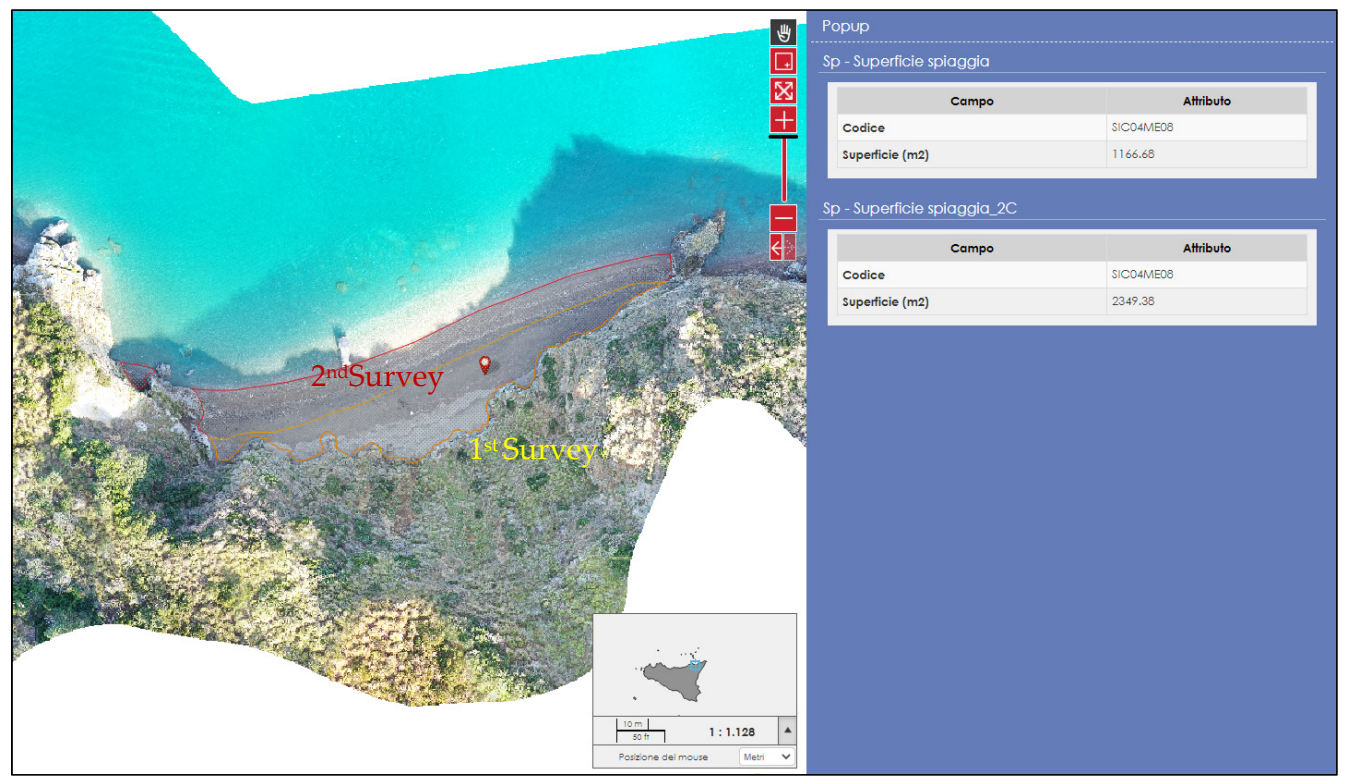

Figure 11. Example of comparison between beach surfaces of two successive surveys made in the PB of Tindari (Messina). 


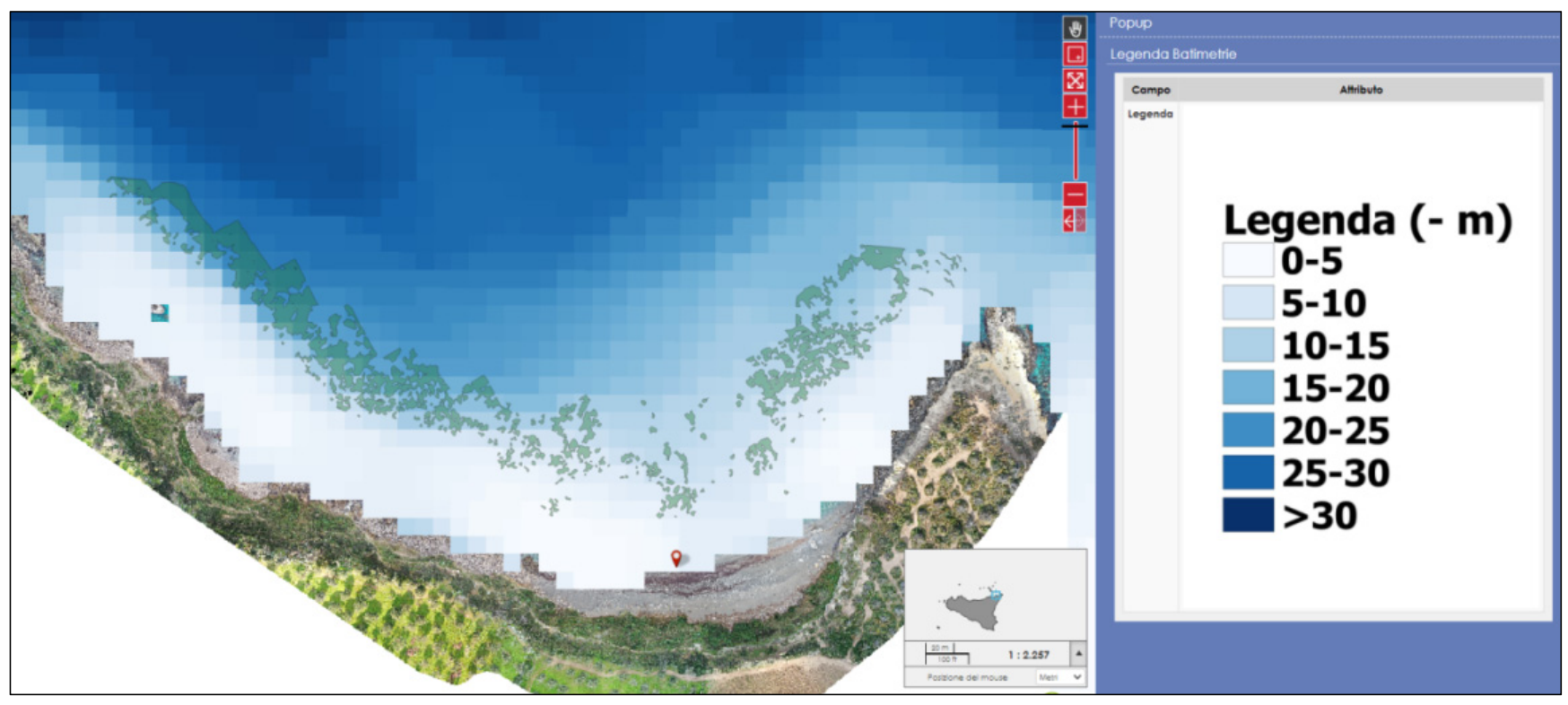

Figure 12. Distribution of Posidonia oceanica according to the various bathymetric zones on the PB of Capo Milazzo (Messina).

\section{Discussion}

While many of the beaches in the Maltese islands are subject to some form of management of varying degrees, (the most established being primarily based on management indicated in the achievement of the Blue Flag beach quality status), there is still a need for an overall holistic management policy and strategy. In Sicily, there is a lack of coastal planning, where coastal management has been focused on local or sectorial erosional rates, which had previously caused severe damage to the natural and archaeological cultural heritage [52]. A very large amount of public funds has been expended on coastal protection without prior consideration of coastal planning to better understand the needs of each individual beach and the interaction of the specific interventions with natural system processes.

The importance of developing (within the BESS project) a monitoring system supported by a surveillance network that specifically targets pocket beaches, is supported by a widespread concern that climate change may be disrupting the stability of otherwise natural systems [72]. Pocket beaches have been defined as ones that have, in their evolution, achieved a sediment balance or a state of equilibrium; they have also been referred to as 'sediment tight' systems. However, with an increasing influence of climate change on natural processes that influence either the arrival of sediments to a pocket beach (such as that via precipitation influenced watersheds) or the potential loss of sediments (such as the wave climate influencing a pocket beach embayment), it is paramount that such potential changes are clearly identified and monitored.

Considering the multiplicity of parameters involved in the study of PBs, and considering their small size, these micro-beaches can be considered as a sentinel system in which, changes in the shape or grain size of the deposit or in the composition of the fauna and flora, could give an indication of the global trend imposed by the effects of climate change. A geospatial database is a fundamental key for the creation of the GIS of the BESS project. All geospatial information acquired at different locations highlighted naturalistic and ecological details of particular interest. Then, they allowed modelling of the beach evolution and the definition of hazard levels in each PB. Such a work on a specific aspect of the much wider coast is clearly highly useful in contributing to a more holistic coastal zone management approach. The relevance of this work is also borne out by the acceptance by the E.U.'s Interreg Italia-Malta funding mechanism to support this initiative aimed at developing a WebGIS for mapping and visualization of coastal data.

In fact, the GIS plays an important and useful role in managing a large amount of parametric data describing PBs. It is, thus, necessary to create a comprehensive data 
management system that allows cross-referencing of information related to different fields interacting in the driving of coastal dynamics processes. WebGIS is an online-distributed system that allows users to access geographic information data by processing services available through a web browser; it has a strong interactivity and dynamics. Compared with traditional GIS software (or online GIS mapping), WebGIS has a wider application range, more timely data updates, lower construction costs, and higher security. Many large internet companies, such as Google, Baidu, and Tencent, recently developed online maps that are based on WebGIS technology for public use [10]. The work described in this paper illustrates the strong potential of such a WebGIS in the manipulation and presentation of a wide set of territorial and marine datasets that may be utilized for more effective understanding and management purposes. Additionally, the WebGIS developed by the BESS project is a particularly useful tool to allow a wider user audience to better appreciate pocket beaches not just visually but also in terms of their functioning and overall complexity; the WebGIS system presents technical data in a manner that will, however, allow both expert and non-expert use, facilitating different levels of manipulation and understanding. The raising of such awareness in the general public has been shown to initiate a process that transforms their initial curiosity into a role of controller and stimulus/driver. On a wider scope, not limited to the PBs, the utility of such a system as WebGIS is much greater.

The lack of interest that is often demonstrated on public items may be countered by increasing interaction with such amenities. The BESS project describes 134 PBs as a territorial database, the evolution of which will hence forth become more visible through the developed website and, in particular, a remote surveillance system; this will allow public monitoring of the evolution of these systems, not only in the territorial sense, but also in terms of the actions taken by local politicians and stakeholders.

The results demonstrate that through the development of the BESS WebGIS, (dedicated only to PBs), it is possible to clearly describe all the geometric and morphological characteristics supported by geological, sedimentological, and bathymetric data. This simple and immediate online geo-database allows a variety of users to access the platform to view and draw as much information as possible. Unlike Desktop GIS, the use of which is limited to a personal computer that contains all the data of a specific project, a WebGIS is accessible remotely via a server, with no restrictions on the place or number of users who access it. WebGIS has the advantage of combining the potential of GIS with the usefulness of the Internet in showing interactive maps and spatial data, as well as any subsequent updates; this clearly makes WebGIS the cheapest and easiest way to distribute geospatial data. The results highlighted how simple and immediate it can be to view the results of related field campaigns once uploaded to a WebGIS platform.

The numerous examples listed demonstrate the effectiveness of WebGIS in comparing the various levels present, which helps to better understand its scientific value and to encourage research in this field. While the knowledge of dynamic evolution of a given layer describes the temporal trend, it is when different types of data are crossed that the potential of the WebGIS grows and multiplies the research ideas. While the BESS WebGIS is undoubtedly useful for those involved in research in this field, its usefulness can be extended to tourism, civil protection, and land-use purposes. Additionally, the BESS WebGIS portal allows:

(1) The creation of a management model extended to a sufficiently large area.

(2) Ensuring that planning is functional to the defense of the natural asset and its conscious and sustainable use.

(3) Making the model implementable continuously, wherever possible involving local administrations, and available to public and private users, using state of the art technologies.

Through the developed WebGIS it will be possible to create a management system for these specific territorial niches, based on an active monitoring plan, at low cost, and with a high technological component. This monitoring-management model is in line with the 
scenarios of future management plans, which will provide for a detailed mapping of the environments concerned, so that protection systems can be created, not necessarily those that are structural, but rather systems based on good continuous management practice exploiting the intrinsic resilience of the system rather than weakening it. The challenge lies precisely in identifying the coastal management systems that make it possible to enhance the intrinsic characteristics of resilience of the beaches. Such systems will allow users to counter the effects of the changes that occur with the sea level rise, as well as with the worsening of marine weather conditions.

GIS has been improving rapidly over the years, but the use and technology development of the Internet still remain the key factors in the development of WebGIS. Only in this way, through a complete involvement of users, will it be possible to aim for an important information and awareness campaign linked to PBs. This will allow for the PBs, ecological pearls, to be monitored and preserved.

\section{Conclusions}

A WebGIS portal including various pocket-beach-related data and models in different temporal and spatial scales was created to present the results of the Interreg project, BESS, to a wider group of people. It is an effective way to share information about Sicilian and Maltese PBs, acquired by the project, and to compare coastal data with each other. The development process suggested that the ease of use, combined with a negligible realization cost, provides an opportunity for replicability and scalability in other geographical and administrative contexts, and also for different purposes. It also proposes that the barriers that limit end-user targets may be addressed though this mechanism, allowing a much wider audience to interact with geographic information data, requiring only an internet service for access; in this manner, not only experts but also those with less informatics skills and less high-performing computers, such as the general public, may interact with this database. The current BESS WebGIS was presented not as a point of arrival, but as a starting point: a platform that must be implemented for the overall management of all coastal data necessary for constant active monitoring. This project suggests that data management will be useful, above all, in predictive terms of the coastal morphological trend, as an effective tool that will support future planning, no longer local, but increasingly on a regional scale. To assist in addressing the project's development toward these directions, a video surveillance system was created, allowing a network of mayors and stakeholders involved with pocket beaches in their territories to become more directly involved with the project and its extensive data. Bringing together various public and private entities in the same direction increases the possibility of giving greater emphasis to coastal problems and identifying solutions. The portal and its further development at a regional level should improve beach-user choices by providing useful data, such as traffic conditions, services, and the quality of each location. The portal should also facilitate the process of initiating Integrated Coastal Zone Management at the local level. This is particularly so in Sicily, where the results of the project and the structure and methodology followed in the BESS project has already been integrated within the Regional Plan Against the Coastal Erosion, which is intended to become the official instrument to manage the coastal area in Sicily.

In addition, various entities will be given the opportunity to actively participate in a process of continuous study and monitoring. End users will have the possibility to view a familiar basemap namely OpenStreetMap, to help them explore the portal by following the specific guidelines. Local public administrations will be able to see the effects of changes in the coastline and, where necessary, plan interventions aimed at the conservation of the coast, which represents a heritage of great importance from a naturalistic and tourist point of view. Probably, defining GIS is a more complex challenge than naming it because the field itself is continually evolving and morphing. It is important to note that the results of the BESS project have been used for implementing the Regional Plan Against the Coastal Erosion (PRCEC with the Italian acronym) and they also contributed to scientific discussions about coastal area management as well. 
Author Contributions: Conceptualization, G.R., A.M. (Anselme Muzirafuti) and S.L.; methodology, M.C., F.G., A.M. (Anselme Muzirafuti), and M.F.; software, M.C., F.G., A.M. (Anselme Muzirafuti) and M.F.; validation, A.M. (Anton Micallef), S.D., A.C., A.Z., O.S., F.I., A.T. and F.C.; formal analysis, A.M. (Anton Micallef), G.R., A.M. (Anselme Muzirafuti) and S.L.; investigation, M.C., F.G., E.C., A.M. (Anselme Muzirafuti) and M.F.; resources, F.G. and M.F.; data curation, M.C., F.G., A.M. (Anselme Muzirafuti) and M.F.; writing-original draft preparation, G.R., A.M. (Anselme Muzirafuti), F.G. and M.F.; writing—review and editing, G.R., A.M. (Anton Micallef) and A.M. (Anselme Muzirafuti); visualization, M.C., S.L. and F.P.C.; supervision, G.R.; project administration, A.Z.; funding acquisition, A.Z. All authors have read and agreed to the published version of the manuscript.

Funding: A.Z. is supported by the European Regional Development Fund (INTERREG Italia-Malta) for the Project BESS: Pocket Beach Management and Remote Surveillance System.

Institutional Review Board Statement: Not applicable.

Data Availability Statement: "BESS project website" at http://bess.pa.ingv.it/?lang=it, accessed on 5 August 2021.

Acknowledgments: This work was partially funded by the European Regional Development Fund (INTERREG Italia-Malta) under the Project BESS: Pocket Beach Management and Remote Surveillance System.

Conflicts of Interest: The authors declare no conflict of interest. The funders had no role in the design of the study; in the collection, analyses, or interpretation of data; in the writing of the manuscript; or in the decision to publish the results.

\section{Appendix A}

Table A1. Summary table of the layers/data present in the GIS.

\begin{tabular}{|c|c|}
\hline Layer & Description \\
\hline Orthophotos and satellite images & $\begin{array}{l}\text { - Acquisition of orthophotos through APR. (two field surveys: Spring-Summer 2019, } \\
\text { Autumn-Winter 2019/2020) } \\
\text { - } \quad \text { Sentinel-2 and Worldview-2 satellite images (Spring-Summer 2019) }\end{array}$ \\
\hline Beach sediment samples & Sedimentological parameters (Folk and Ward [73]). \\
\hline $\begin{array}{l}\text { Geometric and } \\
\text { geomorphological parameters }\end{array}$ & $\begin{array}{l}\text { - Ro-length of the control line/headland spacing/entrance of embayment } \\
\text { - a-bay indentation ("depth" of the bay) } \\
\text { - } \quad \text { am-bay indentation max }(\mathrm{m}) \\
\text { - } \text { S1-Length of embayed shoreline }(\mathrm{m}) \\
\text { - } \quad \text { S1E-External length of embayed shoreline }(\mathrm{m}) \\
\text { - } \text { S2-Length of embayed beach }(\mathrm{m}) \\
\text { - } \quad \text { S2e-Shoreline internal perimeter } \\
\text { - } \text { S2p-Maximum beach width } \\
\text { - } \quad \text { S3-linear distance between the edges of the beach } \\
\text { - Sp-Beach surface } \\
\text { - } \quad \text { CD-closure depth }\end{array}$ \\
\hline Lithology & Within a $1 \mathrm{~km}$ buffer from the shoreline \\
\hline Land use & Extracted from Sentinel-2 images for $500 \mathrm{~m}$ surface from the shoreline. \\
\hline Bathymetry & By satellite images (the degree of precision is related to the quality images) \\
\hline Posidonia oceanica & Mapping of the shallow water Posidonia oceanica, extracted from the clearest orthophotos \\
\hline In situ photo collection & Pictures of the beaches from different point of view \\
\hline Remote surveillance system & $\begin{array}{l}\text { Two types of monitoring systems: photographic/climatic stations and stations with } \\
\text { accelerometer and velocimetric devices }\end{array}$ \\
\hline
\end{tabular}

\section{References}

1. Caiaffa, E. Un Percorso Attraverso Concetti e Nozioni Fondamentali Per Addentrarsi Nel Vasto Mondo Della Scienza Della Informazione Geografica; ENEA: Roma, Italy, 2006; p. 1922.

2. Bhat, M.A.; Shah, R.M.; Ahmad, B. Cloud computing: A solution to geographical information systems (GIS). Inter. J. Comp. Sci. Eng. 2011, 3, 594-600.

3. Dragicevic, S. The potential of Web-based GIS. J. Geogr. Syst. 2004, 6, 79-81. [CrossRef]

4. Barricelli, B.R.; Maiellaro, N.; Padula, M.; Scala, P.L. Dal GIS al WebGIS in Ambiente Open Source. L'edilizia 2009, 23 , 94-97. 
5. De Castro, A.F.; Amaro, V.E.; Grigio, A.M.; Cavalcante, R.G. Modeling and development of a WebGis for environmental monitoring of coastal areas that are influenced by the oil industry. J. Coast. Res. 2011, 64, 1643-1647.

6. Tang, W.; Selwood, J. Connecting Our World: GIS Web Services; ESRI Press: Hong Kong, 2003.

7. Opdam, P. Learning science from practice. Landsc. Ecol. 2010, 25, 821-823. [CrossRef]

8. Veenendaal, B.; Brovelli, M.A.; Li, S. Review of Web Mapping: Eras, Trends and Directions. ISPRS Int. J. Geo-Inf. 2017, 6, 317. [CrossRef]

9. Lopes, S.I.; Moreira, P.M.; Cruz, A.M.; Martins, P.; Pereira, F.; Curado, A. RnMonitor: A WebGIS-based platform for expedite in situ deployment of IoT edge devices and effective Radon Risk Management. In Proceedings of the 2019 IEEE International Smart Cities Conference (ISC2), Casablanca, Morocco, 14-17 October 2019; pp. 451-457.

10. Pan, S.; Wang, K.; Wang, L.; Wang, Z.; Han, Y. Risk Assessment System Based on WebGIS for Heavy Metal Pollution in Farmland Soils in China. Sustainability 2017, 9, 1846. [CrossRef]

11. Howell, R.G.; Petersen, S.L.; Balzotti, C.S.; Rogers, P.C.; Jackson, M.W.; Hedrich, A.E. Using WebGIS to Develop a Spatial Bibliography for Organizing, Mapping, and Disseminating Research Information: A Case Study of Quaking Aspen. Angelands 2019, 41, 244-247. [CrossRef]

12. Seng, B.; Liang, H.; Zhao, Y.; Tang, Y. Design and Implementation of Visualization System for Wastewater Treatment in Dianchi Lake Based on WebGIS. E3S Web Conf. 2019, 118, 04032. [CrossRef]

13. Luo, K.; Zhang, T.; Liu, Y. Design and Implementation of the Water Environment Monitoring and Management System Based on WebGIS for the Four-Lake Basin of Hubei Province. E3S Web Conf. 2019, 136, 06036. [CrossRef]

14. Villani, G.; Nanni, S.; Tomei, F.; Pasetti, S.; Mangiaracina, R.; Agnetti, A.; Leoni, P.; Folegani, M.; Mazzini, G.; Botarelli, L.; et al. The RainBO Platform for Enhancing Urban Resilience to Floods: An Efficient Tool for Planning and Emergency Phases. Climate 2019, 7, 145. [CrossRef]

15. Santoso, M.I.; Gumelar, R.G.; Irawan, B. Development of the WebGIS application for transport infrastructure management in the city of Serang. IOP Conf. Ser. Mater. Sci. Eng. 2019, 673, 012072. [CrossRef]

16. Stanković, R.; Vulović, N.; Lilić, N.; Obradović, I.; Tošović, R.; Pešić-Georgiadis, M. A WebGIS Decision Support System for Management of Abandoned Mines. Energies 2016, 9, 567. [CrossRef]

17. Wirkus, L. An Open Source WebGIS Application for Civic Education on Peace and Conflict. ISPRS Int. J. Geo-Inf. 2015, 4, 1013-1032. [CrossRef]

18. Ahmed, B.; Rahman, M.S.; Islam, R.; Sammonds, P.; Zhou, C.; Uddin, K.; Al-Hussaini, T.M. Developing a Dynamic Web-GIS Based Landslide Early Warning System for the Chittagong Metropolitan Area, Bangladesh. ISPRS Int. J. Geo-Inf. $2018,7,485$. [CrossRef]

19. Lathrop, R.; Auermuller, L.; Trimble, J.; Bognar, J. The Application of WebGIS Tools for Visualizing Coastal Flooding Vulnerability and Planning for Resiliency: The New Jersey Experience. ISPRS Int. J. Geo-Inf. 2014, 3, 408-429. [CrossRef]

20. Oliveira, A.; Jesus, G.; Gomes, G.L.; Rogeiro, J.; Azevedo, A.; Rodrigues, M.; Fortunato, A.B.; Dias, D.M.; Tomas, L.M.; Vaz, L.; et al. An interactive WebGIS observatory platform for enhanced support of integrated coastal management. J. Coast. Res. 2014, 70, 507-512. [CrossRef]

21. Gourmelon, F.; Le Guyader, D.; Fontenelle, G. A dynamic GIS an Efficient Tool for Integrated Coastal zone Management. ISPR Int. J. Geo-Inf. 2014, 3, 391-407. [CrossRef]

22. Hansen, H.S.; Fuglsang, M. An Operational Web-Based Indicator System for Integrated Coastal Zone Management. ISPRS Int. J. Geo-Inf. 2014, 3, 326-344. [CrossRef]

23. Available online: https:/ / webgis.provincia.belluno.it/ (accessed on 5 August 2021).

24. Available online: http:/ / www.webgis.arpa.puglia.it/ (accessed on 5 August 2021).

25. Available online: https://webgis.cittametropolitana.ve.it/lm/ (accessed on 5 August 2021).

26. Peng, Z.R.; Tsou, M. Internet GIS: Distributed Geographic Information Services for the Internet and Wireless Networks; John Wiles and Sons Inc.: Hoboken, NJ, USA, 2003.

27. Haklay, M.; Singleton, A.; Parker, C. Web Mapping 2.0: The Neogeography of the GeoWeb. Geogr. Compass 2008, 2, 2011-2039.

28. Fu, P.; Sun, J. Webgis Principles and Application; ESRI Press: Redlands, CA, USA, 2010.

29. Zhang, X.; Yao, J.; Zhu, C.; Li, Y.; Ding, X. A WebGis for Spatial Data Processing, Analysis and Distribution for Coastal Investigation and Assessment (mission 908) in Jiangsu, China. The International Archives of the Photogrammetry, Remote Sensing and Spatial Information Sciences; Part B4 Beijing, 2008, XXXVII.B. Available online: https:/ /isprs.org/proceedings/XXXVII/congress / 4_pdf/140.pdf (accessed on 5 August 2021).

30. Silverster, R.; Tsuchiya, Y.; Shibano, T. Zeta Bays, Pocket Beaches and Headland Control. In Proceedings of the 17th International Conference on Coastal Engineering, Sydney, Australia, 23-28 March 1980; pp. 1306-1319.

31. Komar, P.D. Rhythmic Shoreline Features and Their Origins. In Mega-Geomorphology; Gardner, R., Scoging, H., Eds.; Clarendon Press: Oxford, UK, 1983; pp. 92-112.

32. Uda, T.; Serizawa, M.; San-Nami, T.; Furuike, K. Shoreline changes of a pocket beach caused by elongationof harbor breackwater and their prediction. Trans. Jpn. Geomorphol. Union 2002, 23, 395-413.

33. Hsu, J.R.C.; Yu, M.J.; Lee, F.C.; Benedet, L. Static Bay beach concept for scientists and engineers: A review. Coast. Eng. 2010, 57, 76-91. [CrossRef]

34. Short, A.D. Role of geological inheritance in Australian beach morphodynamics. Coast. Eng. 2010, 57, 92-97. [CrossRef] 
35. Pranzini, E.; Rosas, V.; Jackson, N.L.; Nordstrom, K.F. Beach changes from sediment delivered by streams to pocketbeaches during a major flood. Geomorphology 2013, 199, 36-47. [CrossRef]

36. Short, A.D.; Masselik, G. Embayed and Structurally Controlled Beaches. In Handbook of Beach and Shoreface Morphodynamics; Short, A.D., Ed.; John Willey \& Sons: New York, NY, USA, 1999; pp. 230-249.

37. Bowman, D.; Rosas, V.; Pranzini, E. Pocket beaches of Elba Island (Italy)—Planview geometry, depth of closure and sediment dispersal. Estuar. Coast. Shelf Sci. 2014, 138, 37-46. [CrossRef]

38. Hsu, J.R.C.; Evans, C. Parabolic bay shapes and applications. Proc. Inst. Civil Eng. 1989, 2, 557-570. [CrossRef]

39. Silvester, R.; Hsu, J.R.C. Coastal Stabilization: Innovative Concepts; Prentice-Hall: Englewood Cliffs, NJ, USA, 1993 ; p. 578.

40. Klein, A.H.F.; Filho, L.B.; Schumacher, D.H. Short-term beach rotation processes in distinct headland bay beach systems. J. Coast. Res. 2002, 18, 442-458.

41. Hsu, J.; Benedet, L.; Klein, A.H.; Raabe, A.; Tsai, C.-P.; Hsu, T. Appreciation of static bay beach concept for coastal management and protection. J. Coast. Res. 2008, 24, 198-215. [CrossRef]

42. Bowman, D.; Guillen, J.; Lopez, L.; Pellegrino, V. Planview Geometry and morphological characteristics of pocket beaches on the Catalan coast (Spain). Geomorphology 2009, 108, 191-199. [CrossRef]

43. Brignone, M.; Schiaffino, C.F.; Isla, F.I.; Ferrari, M. A system for beach video-monitoring: Beachkeeper plus. Comput. Geosci. 2012, 49, 53-61. [CrossRef]

44. Simeone, S.; Palombo, L.; De Falco, G. Morphodynamics of a Nontidal Embayed Beach: The Case Study of Is Arutas (Western Mediterranean). J. Coast. Res. 2013, 29, 63-71. [CrossRef]

45. Cappadonia, C.; Coratza, P.; Agnesi, V.; Soldati, M. Malta and Sicily Joined by Geoheritage Enhancement and Geotourism within the Framework of Land Management and Development. Geosciences 2018, 8, 253. [CrossRef]

46. Furlani, S.; Antonioli, F.; Biolchi, S.; Gambin, T.; Gauci, R.; Lo Presti, V.; Sulli, A. Holocene sea level change in Malta. Quat. Int. 2013, 288, 146-157.

47. Agnesi, V.; Angileri, S.E.; Cappadonia, C.; Coratza, P.; Costanzo, D.; Soldati, M.; Tonelli, C. Geositi nel paesaggio mediterraneo: Confronto tra aree costiere maltesi e siciliane. Cult. Territ. Ling. 2014, 4, 1-12.

48. Randazzo, G. Il canale di Sicilia. In La Costa d'Italia (a cura di S.Ginesu); da Carlo Delfino, E., Ed.; Tavole Nazionali 7: Sassari, Italy, 2011; pp. 79-84.

49. Pedley, M.; Clarke, M.H. Limestone Isles in a Crystal Sea: The Geology of the Maltese Islands; Publishers Enterprises Group: San Gwann, Malta, 2002.

50. Baldassini, N.; Di Stefano, A. Stratigraphic features of the Maltese Archipelago: A synthesis. Nat. Hazards 2017, 86, 203-231. [CrossRef]

51. Lanza, S.; Randazzo, G. Improvements to a Coastal Management Plan in Sicily (Italy): New approaches to borrow sediment management. J. Coast. Res. 2011, 64, 1357-1361.

52. Randazzo, G.; Lanza, S. Regional Plan against Coastal Erosion: A Conceptual Model for Sicily. Land 2020, 9, 307. [CrossRef]

53. House, M.R.; Dunham, K.C.; Wigglesworth, J.C. Geology and Structure of the Maltese Islands. In Malta, A Background for Development; Bowen, J.H., Dewdney, J.C., Fisher, W.B., Eds.; Durham University Press: Durham, UK, $1961 ;$ pp. $24-33$.

54. Ransley, N. A Geography of the Maltese Islands; St. Aloysius College: B'Kara, Malta, 1974; p. 60.

55. Axiak, V.; Gauci, V.; Mallia, A.; Mallia, E.A.; Schembri, P.J.; Vella, A.J. State of the Environment Summary Report for Malta 1998. Environ. Prot. Dept., Min. for the Environment, Floriana (Malta), 1999, p. 130. Available online: https://era.org.mt/wp-content/ uploads /2019/05/SOEReport1998.pdf (accessed on 5 August 2021).

56. Gauci, M.J.; Deidun, A.; Schembri, P.J. Faunistic diversity of Maltese pocket sandy and shingle beaches: Are these of conservation value? Oceanologia 2005, 47, 219-241.

57. Drago, A. Physical Oceanography in the Coastal Waters of the Maltese Islands. In Intergovernmental Oceanographic CommissionInternational Commission on the Scientific Exploration of the Mediterranean Sea (IOC-ICSEM) Workshop on Coastal Erosion; Foundation for International Studies: Valletta, Malta, 1991; pp. 1-5.

58. Micallef, A. Monitoring Beach Stability on the Mediterranean Island of Malta. In Proceedings of the Sixth International Conference on the Mediterranean Coastal Environments, MedCoast'03, Ravenna, Italy, 7-11 October 2003; Ozhan, E., Ed.; Middle East Technical University: Ankara, Turkey, 2003; pp. 1357-1368.

59. Deidun, A.; Schembri, P.J. Long or short? Investigating the effect of beach length and other environmental parameters on macrofaunal assemblages of Maltese pocket beaches. Estuar. Coast. Shelf Sci. 2008, 79, 17-23.

60. Muzirafuti, A.; Cascio, M.; Lanza, S. UAV Photogrammetry-Based Mapping of Sicilian Pocket Beaches: First Approach. In Planet Care from Space; Dessena, M.A., Melis, M.T., Eds.; AIT Series, Trends in Earth Observation; Italian Society of Remote Sensing: Cagliari, Italy, 2021.

61. Muzirafuti, A.; Cascio, M.; Lanza, S. UAV Photogrammetry-based Mapping the Pocket Beach of Isola Bella, Taormina (Northeastern Sicily). In Proceedings of the 2021 IEEE International Workshop on Metrology for the Sea (MetroSea 2021), Reggio Calabria, Italy, 4-6 October 2021.

62. Storlazzi, C.D.; Field, M.E. Sediment distribution and transport along a rocky embayed coast: Monterey Peninsula and Carmel Bay, California. Mar. Geol. 2000, 170, 289-316. [CrossRef]

63. Norcross, Z.M.; Fletcher, C.H.; Merrifield, M. Annual and interannual changes on a reef-fringed pocket beach: Kailua Bay, Hawaii. Mar. Geol. 2002, 190, 553-580. [CrossRef] 
64. Muzirafuti, A.; Barreca, G.; Crupi, A.; Faina, G.; Paltrinieri, D.; Lanza, S.; Randazzo, G. The Contribution of Multispectral Satellite Image to Shallow Water Bathymetry Mapping on the Coast of Misano Adriatico, Italy. J. Mar. Sci. Eng. 2020, 8, 126. [CrossRef]

65. Muzirafuti, A.; Crupi, A.; Lanza, S.; Barreca, G.; Randazzo, G. Shallow Water Bathymetry by Satellite Image: A case Study on the Coast of San Vito Lo Capo Peninsula, Northwestern Sicily, Italy. In Proceedings of the IMEKO TC-19 International Workshop on Metrology for the Sea, Genoa, Italy, 3-5 October 2019.

66. Randazzo, G.; Barreca, G.; Cascio, M.; Crupi, A.; Fontana, M.; Gregorio, F.; Lanza, S.; Muzirafuti, A. Analysis of Very High Spatial Resolution Images for Automatic Shoreline Extraction and Satellite-Derived Bathymetry Mapping. Geosciences 2020, 10, 172. [CrossRef]

67. Lisi, I.; Bruschi, A.; Del Gizzo, M.; Archina, M.; Barbano, A.; Corsini, S. Le unità fisiografiche e le profondità di chiusura della costa italiana. L'ACQUA 2010, 2, 35-52.

68. Tomasello, A.; Cassetti, F.P.; Savona, A.; Pampalone, V.; Pirrotta, M.; Calvo, S.; Signa, G.; Andolina, C.; Mazzola, A.; Vizzini, S.; et al. The use of very high resolution images for studying Posidonia oceanica reefs. Vie Milieu 2020, 70, 25-35.

69. Ventura, D.; Bonifazi, A.; Gravina, M.F.; Belluscio, A.; Ardizzone, G. Mapping and Classification of Ecologically Sensitive Marine Habitats Using Unmanned Aerial Vehicle (UAV) Imagery and Object-Based Image Analysis (OBIA). Remote Sens. 2018, 10, 1331. [CrossRef]

70. Rende, S.F.; Bosman, A.; Di Mento, R.; Bruno, F.; Lagudi, A.; Irving, A.D.; Dattola, L.; Giambattista, L.D.; Lanera, P.; Proietti, R.; et al. Ultra-High-Resolution Mapping of Posidoniaoceanica (L.) Delile Meadows through Acoustic, Optical Data and Object-based Image Classification. J. Mar. Sci. Eng. 2020, 8, 647. [CrossRef]

71. Randazzo, G.; Cascio, M.; Fontana, M.; Gregorio, F.; Lanza, S.; Muzirafuti, A. Mapping of Sicilian Pocket Beaches Land Use/Land Cover with Sentinel-2 Imagery: A Case Study of Messina Province. Land 2021, 10, 678. [CrossRef]

72. Petrişor, A.-I.; Hamma, W.; Nguyen, H.D.; Randazzo, G.; Muzirafuti, A.; Stan, M.-I.; Tran, V.T.; Aştefănoaiei, R.; Bui, Q.-T.; Vintilă, D.-F.; et al. Degradation of Coastlines under the Pressure of Urbanization and Tourism: Evidence on the Change of Land Systems from Europe, Asia and Africa. Land 2020, 9, 275. [CrossRef]

73. Folk, R.L.; Ward, W.C. Brazos River Bar: A study in the significance of grain size parameters. J. Sedim. Petro. 1957, 27, 3-26. [CrossRef] 